\title{
Tepidanaerobacter syntrophicus gen. nov., sp. nov., an anaerobic, moderately thermophilic, syntrophic alcohol- and lactate-degrading bacterium isolated from thermophilic digested sludges
}

\author{
Yuji Sekiguchi, ${ }^{1,2}$ Hiroyuki Imachi, ${ }^{2}$ Ambar Susilorukmi, ${ }^{2,3}$ \\ Mizuho Muramatsu, ${ }^{1}$ Akiyoshi Ohashi, ${ }^{2}$ Hideki Harada, ${ }^{2}$ Satoshi Hanada ${ }^{1}$ \\ and Yoichi Kamagata ${ }^{1,2}$ \\ ${ }^{1}$ Institute of Biological Resources and Functions, National Institute of Advanced Industrial \\ Science and Technology (AIST), Central 6, 1-1-1 Higashi, Tsukuba, Ibaraki 305-8566, Japan \\ ${ }^{2}$ Department of Environmental Systems Engineering, Nagaoka University of Technology, \\ Nagaoka, Niigata 940-2188, Japan \\ ${ }^{3}$ Division of Industrial and Environmental Physics, Indonesian Institute of Sciences, Kompleks \\ LIPI, Bandung 40135, Indonesia
}

Correspondence

Yuji Sekiguchi

y.sekiguchi@aist.go.jp
Three anaerobic, moderately thermophilic, syntrophic primary alcohol- and lactate-degrading microbes, designated strains $\mathrm{JL}^{\top}, \mathrm{JE}$ and $\mathrm{OL}$, were isolated from sludges of thermophilic $\left(55^{\circ} \mathrm{C}\right)$ digesters that decomposed either municipal solid wastes or sewage sludge. The strains were strictly anaerobic organisms. All three strains grew at $25-60^{\circ} \mathrm{C}$ and $\mathrm{pH} 5 \cdot 5-8 \cdot 5$ and optimum growth was observed at $45-50^{\circ} \mathrm{C}$ and $\mathrm{pH} 6 \cdot 0-7 \cdot 0$. The three organisms grew chemo-organotrophically on a number of carbohydrates in the presence of yeast extract. In co-culture with the hydrogenotrophic methanogen Methanothermobacter thermautotrophicus, all strains could utilize ethanol, glycerol and lactate syntrophically for growth, although these compounds were not metabolized in pure culture without additional external electron acceptors. All strains could reduce thiosulphate. Quinones were not detected. The DNA $G+C$ contents of strains $\mathrm{JL}^{\top}, \mathrm{JE}$ and $\mathrm{OL}$ were $38 \cdot 0,37 \cdot 3$ and $37 \cdot 7 \mathrm{~mol} \%$, respectively. Major cellular fatty acids of the strains were iso- $C_{15: 0}, C_{16: 0}$ and unsaturated species of $C_{15: 1}$. Phylogenetic analyses based on 16S rRNA gene sequences revealed that the strains belong to a deeply branched lineage of the phylum Firmicutes; the most closely related species was Thermovenabulum ferriorganovorum (16S rRNA gene sequence similarity of $88 \%$ ). The three strains were phylogenetically very closely related to each other (99-100\% 16S rRNA gene sequence similarity) and were physiologically and chemotaxonomically similar. These genetic and phenotypic properties suggest that the strains should be classified as representatives of a novel species and genus; the name Tepidanaerobacter syntrophicus gen. nov., sp. nov. is proposed. The type strain of Tepidanaerobacter syntrophicus is strain $\mathrm{JL}^{\top}\left(=\mathrm{JCM} 12098^{\top}=\mathrm{NBRC}_{100060^{\top}}=\mathrm{DSM} 15584^{\top}\right)$.
Methanogenic degradation of organic compounds (such as fatty acids, aromatics and alcohols) often depends on close interactions among different trophic groups of anaerobes (Schink, 1997; Stams, 1994). Syntrophic association between two metabolic groups, such as syntrophic fatty-acid-oxidizing bacteria and hydrogenotrophic methanogens, is a typical

The GenBank/EMBL/DDBJ accession numbers for the $16 \mathrm{~S}$ rRNA gene sequences of strains $\mathrm{JE}, \mathrm{JL}^{\top}$ and $\mathrm{OL}$ are respectively AB106352-AB106354.

Photomicrographs of strains JE and OL cultivated anaerobically with sucrose and yeast extract at $45^{\circ} \mathrm{C}$ are available as supplementary material in IJSEM Online. example of such symbioses that can be found ubiquitously in methanogenic ecosystems. The isolation of 'S organism' from 'Methanobacillus omelianskii' cultures in 1967 provided the first tangible evidence of syntrophic substrate degradation (Bryant et al., 1967). Although the 'S organism' was lost and hence its exact taxonomic placement remains unknown, the organism was characterized as a Gramnegative, strictly anaerobic, oval-rod-shaped bacterium that could catalyse syntrophic degradation of ethanol and other primary aliphatic alcohols (Reddy et al., 1972). Since the discovery of 'S organism', a number of species catalysing the syntrophic degradation of primary alcohols has been cultivated and characterized (Schink, 1997). In addition to 
'S organism' and other unnamed strains (Plugge et al., 1990; Wu et al., 1992), sulphate-reducing species of the genus Desulfovibrio (Bryant et al., 1977) and some members of the genera Pelobacter (Schink \& Stieb, 1983; Schink, 1984, 1985), Acetobacterium (Eichler \& Schink, 1984) and Syntrophobacter (Wallrabenstein et al., 1995) strains perform syntrophic alcohol degradation in co-culture with hydrogenotrophic methanogens under mesophilic conditions. Furthermore, some members of the genera Desulfotomaculum (Klemps et al., 1985), Thermoanaerobacter (BenBassat et al., 1981) and Pelotomaculum (Imachi et al., 2002) degrade primary alcohols syntrophically under thermophilic conditions. It has been reported that ethanol degradation in methanogenic ecosystems, particularly in those under thermophilic conditions, is often an important step in methanogenesis, accounting for a large proportion of electrons derived from degradation of complex organic compounds (Stams \& Zehnder, 1990). Since natural and man-made methanogenic ecosystems contain a vast array of uncultured bacteria (Sekiguchi \& Kamagata, 2004), it is important to elucidate those species responsible for major degradation steps in the ecosystem and to expand our knowledge further of the diversity of syntrophic microbes residing in various anaerobic environments. Therefore, we attempted to cultivate various novel syntrophs from a variety of anaerobic ecosystems. During the surveys of novel syntrophic organisms, three novel strains capable of degrading primary aliphatic alcohols and lactate in coculture with hydrogenotrophic methanogens were found. In the present study, detailed morphological, physiological and chemotaxonomic characteristics of the strains isolated are reported and a novel species and genus are proposed to accommodate them.

Strains $\mathrm{JL}^{\mathrm{T}}$ and JE were originally obtained from sludge of a full-scale thermophilic $\left(55^{\circ} \mathrm{C}\right)$ digester that decomposed municipal solid wastes (sludge J, from Niigata, Japan). Strain OL was isolated from sludge of a full-scale digester that degraded sewage sludge under thermophilic $\left(55^{\circ} \mathrm{C}\right)$ conditions (sludge $\mathrm{O}$, from Osaka, Japan). Methanothermobacter thermautotrophicus strain $\Delta \mathrm{H}^{\mathrm{T}}\left(=\mathrm{DSM} 1053^{\mathrm{T}}\right)$ was obtained from the DSMZ, Braunschweig, Germany. Methanothermobacter thermautotrophicus strain type II was isolated and maintained in our laboratory. The basal medium used for enrichment, isolation and maintenance of strains $\mathrm{JL}^{\mathrm{T}}$, JE and OL was prepared based on that of Widdel \& Pfennig (1981). The medium composition was as described previously (Sekiguchi et al., 2000). Primary enrichment cultures were incubated anaerobically at $55^{\circ} \mathrm{C}$. All incubations were carried out at $45^{\circ} \mathrm{C}$ in $50 \mathrm{ml}$ serum vials containing $20 \mathrm{ml}$ medium $\left(\mathrm{pH}_{25^{\circ} \mathrm{C}} 7 \cdot 0\right)$ under an atmosphere of $\mathrm{N}_{2} / \mathrm{CO}_{2}(80 / 20, \mathrm{v} / \mathrm{v})$, unless otherwise mentioned. Neutralized substrates were added to vials containing basal medium from stock solutions prior to inoculation. Solid medium was prepared by adding purified agar (Agar noble; Difco) to the medium as described above at a final concentration of $20 \mathrm{~g} \mathrm{l}^{-1}$. M. thermautotrophicus strains were cultivated at $55^{\circ} \mathrm{C}$ using the same media used for strains $\mathrm{JL}^{\mathrm{T}}$, JE and $\mathrm{OL}$ except that hydrogen (approx. $0 \cdot 5-1 \cdot 0$ atm or $50-100 \mathrm{kPa}$ ) was added to the gas phase $\left(80 / 20, \mathrm{v} / \mathrm{v}, \mathrm{N}_{2} / \mathrm{CO}_{2}\right)$ in the vials as an energy source.

To determine the optimum $\mathrm{pH}$ for growth of strains $\mathrm{JL}^{\mathrm{T}}$, JE and $\mathrm{OL}$, the $\mathrm{pH}$ of the autoclaved medium containing $20 \mathrm{mM}$ sucrose and $0 \cdot 01 \%$ yeast extract was adjusted at room temperature to $\mathrm{pH} 5 \cdot 0-9 \cdot 0$ by adding $\mathrm{HCl}$ or $\mathrm{NaOH}$ under a $100 \% \mathrm{~N}_{2}$ atmosphere prior to inoculation. During incubation, the $\mathrm{pH}$ of the medium was routinely monitored to check whether the initial $\mathrm{pH}$ conditions had changed. To evaluate the optimum temperature for growth, isolates were cultivated anaerobically in sucrose plus yeast extract medium $\left(\mathrm{pH}_{25}{ }^{\circ} \mathrm{C} 7 \cdot 0\right)$ at $17,20,25,37,45,50,55,60,70$ and $80{ }^{\circ} \mathrm{C}$. Under all conditions, duplicate cultures $(1 \%$ inoculum) were used and $\mathrm{OD}_{400}$ was measured. To test growth and substrate utilization, autoclaved or filtersterilized substrates were added to the medium. All cultures were incubated anaerobically at $55^{\circ} \mathrm{C}, \mathrm{pH}_{25}{ }^{\circ} \mathrm{C} \cdot 0$ for at least 4 weeks. All substrates, including Fe(III) NTA (nitrilotriacetate) (Roden \& Lovley, 1993), were prepared as described previously (Sekiguchi et al., 2000). Growth and substrate utilization of the strains were determined by monitoring the increase in turbidity $\left(\mathrm{OD}_{400}\right)$ and the production of acetate. In syntrophic growth/substrate utilization tests, M. thermautotrophicus cells were added to the medium ( $2 \%$ inoculum); growth and substrate utilization were checked by measuring turbidity $\left(\mathrm{OD}_{400}\right)$ and methane production.

Cell morphology was examined under a phase-contrast microscope (Olympus AX80T). The Gram-staining reaction was performed by Hucker's method (Doetsch, 1981). Phasecontrast micrographs were taken using wet mounts on agarcoated slides (Pfenning \& Wagener, 1986) for exponentialphase cultures. Cells for thin-section electron microscopy were prepared as described previously (Sekiguchi et al., 2003). Short-chain fatty acids, methane, hydrogen and carbon dioxide were determined by GC (Sekiguchi et al., 2000). Determination of alcohols and other compounds was performed by HPLC as described previously (Imachi et al., 2002). For $\mathrm{G}+\mathrm{C}$ content determination, DNA was extracted and purified according to Kamagata \& Mikami (1991). The $\mathrm{G}+\mathrm{C}$ content was determined by HPLC (Shimadzu LC-6A) with a UV detector (Shintani et al., 2000). A mean value was calculated from two independent experiments. Quinones were determined as described previously (Zhang et al., 2000). Cells for quinone analysis were harvested from cultures grown on medium containing lactate and thiosulphate. Fatty acids of cells were converted to methyl esters using $\mathrm{HCl} /$ methanol and identified by GC-MS (Hitachi M7200A FC/3DQMS system) (Hanada et al., 2002). Cells were harvested from cultures grown on the medium containing sucrose plus yeast extract at $45^{\circ} \mathrm{C}$.

For 16S rRNA gene sequencing, genomic DNA of the strains, as well as that from enrichment cultures, was recovered according to the method of Hiraishi (1992). 16S rRNA genes were amplified by PCR with Taq polymerase (Perkin Elmer) as described previously (Sekiguchi et al., 2000). The PCR 
primers used in the amplification were the bacterial domain universal primer 8F (5'-AGAGTTTGATCCTGGCTCAG3'; positions 8-27 in Escherichia coli) and the prokaryote universal primer 1490R (5'-GGTTACCTTGTTACGACTT3'; 1491-1509 in E. coli) (Weisburg et al., 1991). The PCR product was sequenced directly on a Beckman CEQ8000 DNA sequencer using a CEQ DTC quick start kit (Beckman Coulter). Sequence data were aligned in an ARB dataset using the ARB program package and aligned data were corrected manually using the editing tool in the package. Phylogenetic trees based on 16S rRNA gene sequences were constructed by the neighbour-joining method (Saitou \& Nei, 1987) with the ARB program package (Ludwig et al., 2004). Bootstrap resampling analysis (Felsenstein, 1985) for 1000 replicates was performed with the neighbour-joining, maximumparsimony and maximum-likelihood methods to estimate the confidence of tree topologies as described previously (Zhang et al., 2003) with slight modifications, i.e. the neighbour-joining and the maximum-parsimony methods were used with the PAUP ${ }^{\star} 4.0$ package (Swofford, 2003) and the maximum-likelihood method was used with the TREEFINDER program package (Jobb et al., 2004).

Thermophilic sludges $\left(55^{\circ} \mathrm{C}\right)$ were taken from two different types (sludges $\mathrm{J}$ and $\mathrm{O}$ ) of full-scale anaerobic digesters fed with organic solid wastes. Gently washed and homogenized sludges were used for primary enrichments using $20 \mathrm{mM}$ lactate or $20 \mathrm{mM}$ ethanol as substrate and the cultures were incubated anaerobically at $55^{\circ} \mathrm{C}$ (enrichment $\mathrm{JL}$, lactate culture with sludge J; enrichment JE, ethanol culture with sludge J; enrichment OL, lactate culture with sludge $\mathrm{O}$; enrichment OE, ethanol culture with sludge O). Growth and methane production were observed from all four cultures within a week of inoculation. The cultures were further enriched by successive transfers using a $1 \%$ inoculum. All the enrichments stably converted their respective substrates into acetate and methane over ten successive transfers. Enrichments JL, JE and OL contained at least two major cell morphotypes. One was a non-motile, $\mathrm{F}_{420}$-autofluorescent rod morphologically resembling species in the genus Methanothermobacter and the other was an irregular rod (identified later as a syntrophic bacterium). Enrichment OE contained cells with morphotypes that differed from those of cells of enrichments JL, JE, and OL. Further study was conducted only for enrichments JL, JE and OL. To purify the irregular rods in the three enrichment cultures, an attempt was made to cultivate them in pure culture with other substrates that could support their growth in axenic culture (without methanogens). Highly purified cultures of enrichments JL, JE and OL after more than ten successive transfers were serially diluted and inoculated in media containing various substrates, such as pyruvate, glucose, crotonate and lactate plus sulphate. In the presence of $0.01 \%$ yeast extract, various carbohydrates such as glucose and sucrose supported growth of rod-shaped cells, the morphology of which was very similar to that of the irregular rods in the original enrichment cultures. Growth of cultures on the glucose/ yeast extract medium could be observed within 2-3 days of incubation at $55^{\circ} \mathrm{C}$. After three successive transfers on the glucose/yeast extract medium, roll-tube isolation was performed. Small colonies that were white, lens-shaped and $0.5 \mathrm{~mm}$ in diameter formed after 1 week of incubation. This step was repeated several times and the purified strains, designated $\mathrm{JL}^{\mathrm{T}}$, JE and OL, were obtained from enrichments JL, JE and OL, respectively.

Strain $\mathrm{JL}^{\mathrm{T}}$ cells were irregular rods, $1 \cdot 5-10 \cdot 0 \mu \mathrm{m}$ in length and $0 \cdot 6-0 \cdot 8 \mu \mathrm{m}$ wide (Fig. 1a). Cells of strain JE were $1 \cdot 5-$ $40.0 \mu \mathrm{m}$ long and $0 \cdot 6-0.8 \mu \mathrm{m}$ wide (see Supplementary Fig. S1 in IJSEM Online) and cells of strain OL were $1 \cdot 5-10 \cdot 0 \mu \mathrm{m}$ long and $0 \cdot 6-0 \cdot 8 \mu \mathrm{m}$ wide (Supplementary Fig. S1). The length of the cells seemed to depend on the growth phase. Spore formation was not observed and Gramstaining was negative for all the isolates. Motility was not observed with any isolate. Electron microscopy demonstrated that cells of all three isolates possessed a Grampositive-type cell wall (Fig. 1b).

Strain $\mathrm{JL}^{\mathrm{T}}$ grew on glucose/yeast extract medium between 25 and $60{ }^{\circ} \mathrm{C}$, with optimum growth at $45-50{ }^{\circ} \mathrm{C}$, whereas no growth was observed below 25 or above $60^{\circ} \mathrm{C}$ after 4 weeks of incubation. The $\mathrm{pH}$ range for growth was between 5.5 and $8 \cdot 5$, with optimum growth around $\mathrm{pH} 7 \cdot 0$. Strain $\mathrm{JL}^{\mathrm{T}}$ was a strictly anaerobic organism: no growth occurred in the

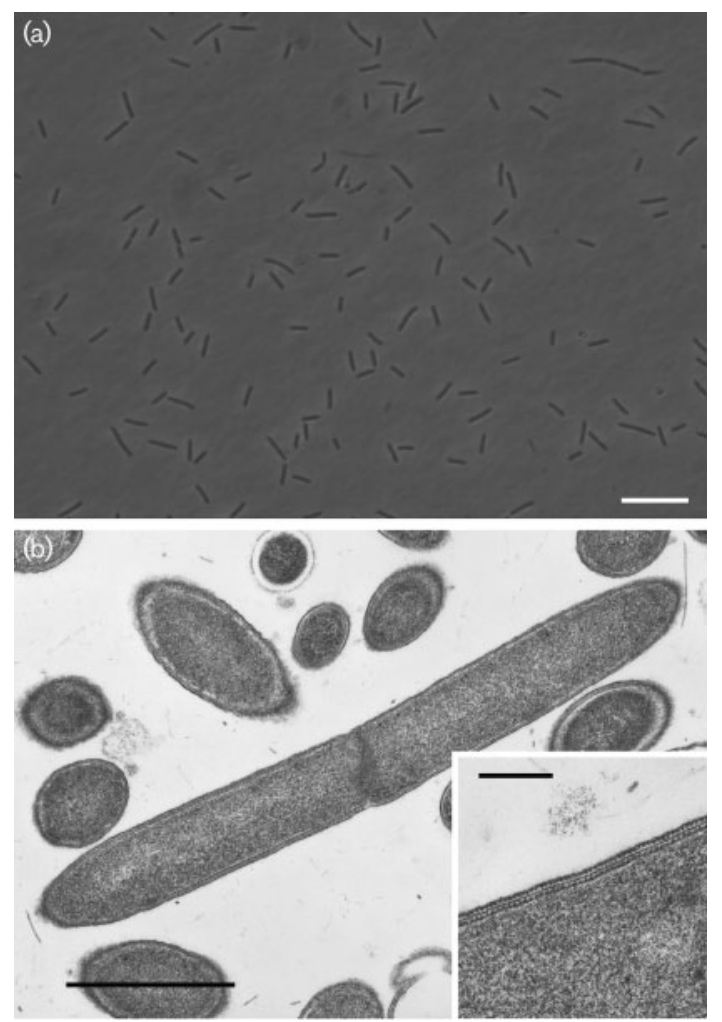

Fig. 1. Phase-contrast micrograph (a) (bar, $10 \mu \mathrm{m})$ and transmission electron micrographs (b) (bar in main photo, $1 \mu \mathrm{m}$; bar in inset, $0.2 \mu \mathrm{m}$ ) of strain $\mathrm{JL}^{\top}$. 
presence of oxygen $(20 \%, \mathrm{v} / \mathrm{v}$, in the gas phase). It was not photosynthetic (data not shown). Yeast extract was strictly required for growth and it could not be replaced with vitamin mixtures. In the presence of yeast extract $(0 \cdot 01 \%)$, growth and substrate utilization were observed with the following substrates (at $20 \mathrm{mM}$ unless indicated) under optimum conditions $\left(45^{\circ} \mathrm{C}, \mathrm{pH} 7 \cdot 0\right)$ : crotonate, glucose, ribose, xylose, fructose, galactose, mannose, raffinose, sucrose, starch $\left(5 \mathrm{~g} \mathrm{l}^{-1}\right)$ and pectin $\left(5 \mathrm{~g} \mathrm{l}^{-1}\right)$. Weak growth occurred with either malate or arabinose (both at $20 \mathrm{mM})$ in medium supplemented with yeast extract $(0.01 \%)$. Growth and acid formation were not observed with the following substrates (at $20 \mathrm{mM}$ unless indicated) in the presence of yeast extract $(0.01 \%)$ : yeast extract alone $(0 \cdot 5 \%)$, Casamino acids $(0 \cdot 1 \%), \mathrm{H}_{2} / \mathrm{CO}_{2}(1 \mathrm{~atm}$ or $101 \mathrm{kPa})$ plus acetate $(5 \mathrm{mM})$, tryptone $(0 \cdot 1 \%)$, betaine $(10 \mathrm{mM})$, pyruvate, lactate, glycerol $(5 \mathrm{mM})$, acetate, propionate, butyrate, succinate, fumarate, ethanol, methanol, 1-propanol, 1-butanol, benzoate $(5 \mathrm{mM})$, hydroquinone (1 mM), 1,3-benzenediol ( $1 \mathrm{mM})$, phenol (1 mM), or formate $(20 \mathrm{mM})$ plus acetate $(5 \mathrm{mM})$. In glucose medium supplemented with yeast extract $(0 \cdot 01 \%)$, cells of strain $\mathrm{JL}^{\mathrm{T}}$ produced acetate, hydrogen and an unidentifiable substance (detected by HPLC) as the main end products; typical reduced products such as lactate and ethanol were not detected.

In co-culture with hydrogenotrophic methanogens $M$. thermautotrophicus strain $\Delta \mathrm{H}^{\mathrm{T}}$ or type II, the organism could grow at $45^{\circ} \mathrm{C}$ and $\mathrm{pH} 7 \cdot 0$ with ethanol $(20 \mathrm{mM})$, glycerol $(5 \mathrm{mM})$ and lactate $(20 \mathrm{mM})$. Since cells of strain $\Delta \mathrm{H}^{\mathrm{T}}$ could not utilize formate as an energy source (though strain type II could), interspecies formate transfer did not seem to be essential for the syntrophic growth of strain $\mathrm{JL}^{\mathrm{T}}$. As shown in Fig. 2(a), 20 mM lactate was degraded almost completely and transformed into acetate and methane within 2 weeks of incubation in co-culture with hydrogenotrophic methanogens (electron recovery, $92 \%$; carbon recovery, $79 \%$, on the basis of lactate consumed and methane and acetate formed). However, in pure culture, acetate and hydrogen production from lactate stopped when hydrogen accumulated at approximately 0.02 atm $(2 \mathrm{kPa})$ and lactate was not degraded further (Fig. 2b). Acetate, propionate, butyrate, methanol, 1-propanol, 1-butanol, 1,3propanediol, 2,3-butanediol (all at $20 \mathrm{mM}$ ) and benzoate $(5 \mathrm{mM})$ did not support growth of syntrophic cultures of strain $\mathrm{JL}^{\mathrm{T}}$. The following compounds were tested as electron acceptors with lactate and $0.01 \%$ yeast extract medium $\left(45^{\circ} \mathrm{C}, \mathrm{pH} \mathrm{7 \cdot 0):} 20 \mathrm{mM}\right.$ sulphate, $20 \mathrm{mM}$ nitrate, $1 \mathrm{mM}$ sulphite, $20 \mathrm{mM}$ thiosulphate and $5 \mathrm{mM} \mathrm{Fe}$ (III) NTA. Only thiosulphate supported growth of strain $\mathrm{JL}^{\mathrm{T}}$.

The above tests were also performed for the other two strains (JE and OL) and the physiological traits of all three strains are summarized in Table 1. As shown in Table 1, there were few differences in phenotypic features of the three strains. A few differences in substrate utilization were found among the strains, e.g. utilization of crotonate, ribose, malate, arabinose, galactose and raffinose. All strains utilized the same substrates (primary alcohols and lactate) in co-culture with methanogens. All strains used thiosulphate as an electron acceptor. In addition, all strains had similar growth responses to $\mathrm{pH}$ and temperature.

The DNA G $+\mathrm{C}$ contents of strains $\mathrm{JL}^{\mathrm{T}}$, JE, and OL were calculated to be $38 \cdot 0,37 \cdot 3$ and $37 \cdot 7 \mathrm{~mol} \%$, respectively. Fatty acid methyl ester analysis showed that strain $\mathrm{JL}^{\mathrm{T}}$ contained iso- $\mathrm{C}_{15: 0}(23 \%), \mathrm{C}_{16: 1}(\Delta 9)$ cis $(11 \%)$ and unsaturated derivatives of $\mathrm{C}_{15: 1}(25 \%)$ as the major fatty acids; minor fatty acids were $\mathrm{C}_{14: 0}(6 \%), \mathrm{C}_{15: 0}(3 \%), \mathrm{C}_{16: 0}(6 \%)$, unsaturated isomers of $\mathrm{C}_{17: 1}(11 \%), \mathrm{C}_{17: 0}(3 \%), \mathrm{C}_{18: 0}$ $(1 \%), \mathrm{C}_{13: 0}(1 \%), \mathrm{C}_{18: 1}(\Delta 9)$ cis $(2 \%)$, an unsaturated isomer of $\mathrm{C}_{16: 1}(3 \%)$ and an unsaturated isomer of $\mathrm{C}_{14: 1}$ $(5 \%)$. The major fatty acids of cells of strain JE were iso$\mathrm{C}_{15: 0}(39 \%), \mathrm{C}_{16: 0}(14 \%)$ and unsaturated derivatives of $\mathrm{C}_{15: 1}(15 \%)$; minor fatty acids were $\mathrm{C}_{14: 0}(8 \%), \mathrm{C}_{15: 0}$ $(6 \%), \mathrm{C}_{17: 0}(5 \%)$, unsaturated isomers of $\mathrm{C}_{17: 1}(4 \%)$, $\mathrm{C}_{18: 0}(3 \%), \mathrm{C}_{16: 1}(\Delta 9)$ cis $(3 \%), \mathrm{C}_{13: 0}(1 \%)$, an unsaturated isomer of $\mathrm{C}_{16: 1}(1 \%)$ and an unsaturated isomer of $\mathrm{C}_{14: 1}(1 \%)$. The major fatty acids of cells of strain OL were iso- $\mathrm{C}_{15: 0}(21 \%), \mathrm{C}_{17: 0}(13 \%), \mathrm{C}_{16: 0}(13 \%)$ and unsaturated derivatives of $\mathrm{C}_{15: 1}(12 \%)$; minor fatty acids were
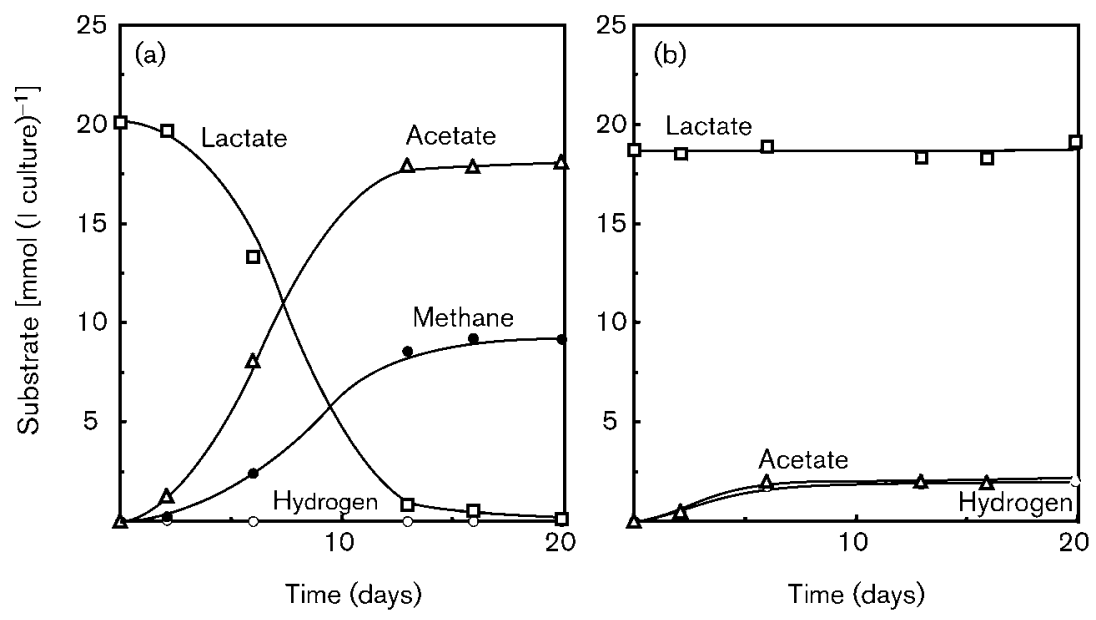

Fig. 2. Degradation of lactate by strain $\mathrm{JL}^{\top}$ in the presence (a) and absence (b) of the methanogen Methanothermobacter thermautotrophicus strain type II. 
$\mathrm{C}_{15: 0}(9 \%), \mathrm{C}_{14: 0}(8 \%)$, unsaturated isomers of $\mathrm{C}_{16: 1}(\Delta 9)$ cis $(6 \%), \mathrm{C}_{17: 1}(6 \%), \mathrm{C}_{18: 1}(\Delta 9)$ cis $(4 \%), \mathrm{C}_{18: 0}(3 \%)$, an unsaturated isomer of $\mathrm{C}_{16: 1}(2 \%)$, an unsaturated isomer of $\mathrm{C}_{14: 1}(2 \%)$ and $\mathrm{C}_{13: 0}(1 \%)$. Quinones were not detected in any of the strains.

For strains $\mathrm{JL}^{\mathrm{T}}$, JE and OL, a total of $1451 \mathrm{nt}$ of the $16 \mathrm{~S}$ rRNA gene was sequenced and phylogenetic analyses revealed that the strains belong to a deeply branched lineage of the phylum Firmicutes, forming a coherent clade with members of the genera Thermovenabulum and Thermosediminibacter (Fig. 3). The most closely related species were Thermovenabulum ferriorganovorum (Zavarzina et al., 2002) (16S rRNA gene sequence similarity of $88 \%$ ) and species of the genus Thermosediminibacter ( $87 \%$ similarity) (Fig. 3), indicating the novelty of our strains at the genus level. All the isolated strains were phylogenetically very closely related to each other (99-100\% similarity). Direct sequencing of bacterial $16 \mathrm{~S}$ rRNA genes from the highly purified enrichment cultures (JL, JE and OL) indicated that the cultures contained bacteria whose $16 \mathrm{~S}$ rRNA genes matched perfectly with those of the isolates in this study as the major bacterial population. This fact suggested that the strains obtained were the irregular rods found in the primary enrichment cultures.

Phenotypic and genetic analyses of all the strains isolated in this study showed the phylogenetic and chemotaxonomic novelty of strains $\mathrm{JL}^{\mathrm{T}}$, JE and OL. The strains were moderately thermophilic, heterotrophic anaerobes that could decompose various carbohydrates in the presence of yeast extract. In co-culture with hydrogenotrophic methanogens, all the strains could degrade ethanol, glycerol and lactate syntrophically. Under methanogenic conditions, alcohols such as primary aliphatic alcohols and lactate could be degraded through both syntrophy between substratedegrading, hydrogen-forming bacteria and hydrogenotrophic methanogens and fermentative degradation of alcohols and lactate to fatty acids as reduced end products (Eichler \& Schink, 1984). Regarding the first type of metabolism, various thermophilic microbes capable of syntrophic degradation of lactate and primary alcohols have been described. For example, a thermophilic species of the sulphate-reducing genus Desulfotomaculum (Desulfotomaculum nigrificans) is also known to degrade ethanol and lactate in the absence of sulphate when the culture is co-cultivated with hydrogenotrophic methanogens (Klemps et al., 1985). Thermoanaerobacter brockii (formerly Thermoanaerobium brockii) was originally isolated as a thermophilic chemo-organotroph that could degrade various carbohydrates fermentatively (Cayol et al., 1995; Zeikus et al., 1979). Later, the organism was found to degrade ethanol only in co-culture with hydrogenotrophic methanogens (BenBassat et al., 1981). However, syntrophic growth properties of other species within the genus Thermoanaerobacter have not been examined and, hence, the ability of other members of this genus to grow syntrophically is unknown. Our strains could utilize carbohydrates in addition to their ability to grow syntrophically. These traits seem to be physiologically similar to those of members of the genus Thermoanaerobacter rather than to those of other known syntrophic ethanol- and lactate-degraders. Members of the genus Thermoanaerobacter are also known to utilize thiosulphate as an electron acceptor, as observed in our strains (Jain \& Zeikus, 1992). However, our strains were apparently distinct at the genus level from members of the genus Thermoanaerobacter in the following features: (i) the optimum growth temperature of our strains is much lower $\left(45-50{ }^{\circ} \mathrm{C}\right)$ than those of members of the genus Thermoanaerobacter $\left(65-75^{\circ} \mathrm{C}\right)$ (Jain \& Zeikus, 1992); (ii) our strains did not form a monophyletic group with members of the genus Thermoanaerobacter on the basis of 16S rRNA gene sequences; and (iii) the sequence similarities between 16S rRNA genes of our strains and Thermoanaerobacter species were less than $85 \%$ (Fig. 3). Phylogenetically, the most closely related species was Thermovenabulum ferriorganovorum, which was isolated from a terrestrial hydrothermal source as a thermophilic anaerobe (Zavarzina et al., 2002). Thermovenabulum ferriorganovorum can utilize various carbohydrates fermentatively. Although Thermovenabulum ferriorganovorum and our strains share some basic physiological traits (such as anaerobic and saccharolytic growth), the following notable differences between them were found (Table 1). Thermovenabulum ferriorganovorum cells are straight or sometimes branched rods that form spores, whereas our strains are straight rods or filaments that do not form spores. Thermovenabulum ferriorganovorum grows at $45-76^{\circ} \mathrm{C}$, with optimum growth at $63-65^{\circ} \mathrm{C}$, whereas our strains are moderately thermophilic $\left(25-60^{\circ} \mathrm{C}\right.$ with an optimum of $45-50^{\circ} \mathrm{C}$ ). In addition, Thermovenabulum ferriorganovorum reduces various oxidized forms of sulphur, nitrogen and metals, whereas our strains can reduce thiosulphate only. Other related thermophilic chemo-organotrophs in the genus Thermosediminibacter also show physiological traits that are similar to those of our strains, such as fermentative growth with various monomeric carbohydrates (Lee et al., 2005). However, although similar to Thermovenabulum ferriorganovorum, there are a number of phenotypic differences between our strains and these anaerobes (as shown in Table 1). On the basis of the phenotypic and phylogenetic distinctiveness of our isolates, it is concluded that the strains represent a novel and distinct taxon at the genus level in a deeply branched lineage of the phylum Firmicutes. Significant phenotypic and genetic differences among strains $\mathrm{JL}^{\mathrm{T}}, \mathrm{JE}$ and $\mathrm{OL}$ were not clearly found (Table 1). All their major physiological, chemotaxonomic and genetic properties (16S rRNA genes) were very similar to each other. Based on these findings, it seems justifiable that all three strains should be classified into one species. Hence, the name Tepidanaerobacter syntrophicus gen. nov., sp. nov. is proposed. The type strain is strain $\mathrm{JL}^{\mathrm{T}}$.

Strains $\mathrm{JL}^{\mathrm{T}}$, JE and $\mathrm{OL}$ were isolated from sludges of thermophilic anaerobic digesters in which high-strength organic solid wastes were digested. It is known that ethanol 
Table 1. Characteristics of strains $\mathrm{JL}^{\top}, \mathrm{JE}$ and $\mathrm{OL}$ and members of the related genera Thermovenabulum, Thermosediminibacter and Thermoanaerobacter

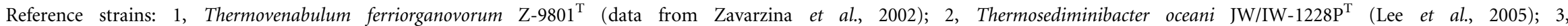
Thermosediminibacter litoriperuensis JW/YJL-1230-7/2 ${ }^{\mathrm{T}}$ (Lee et al., 2005); 4, Thermoanaerobacter brockii subsp. brockii HTD4 ${ }^{\mathrm{T}}$ (Zeikus et al., 1979; Cayol et al., 1995). Only differences found among the strains shown are listed. -, Negative; \pm , weakly positive; + , positive; ND, no data available.

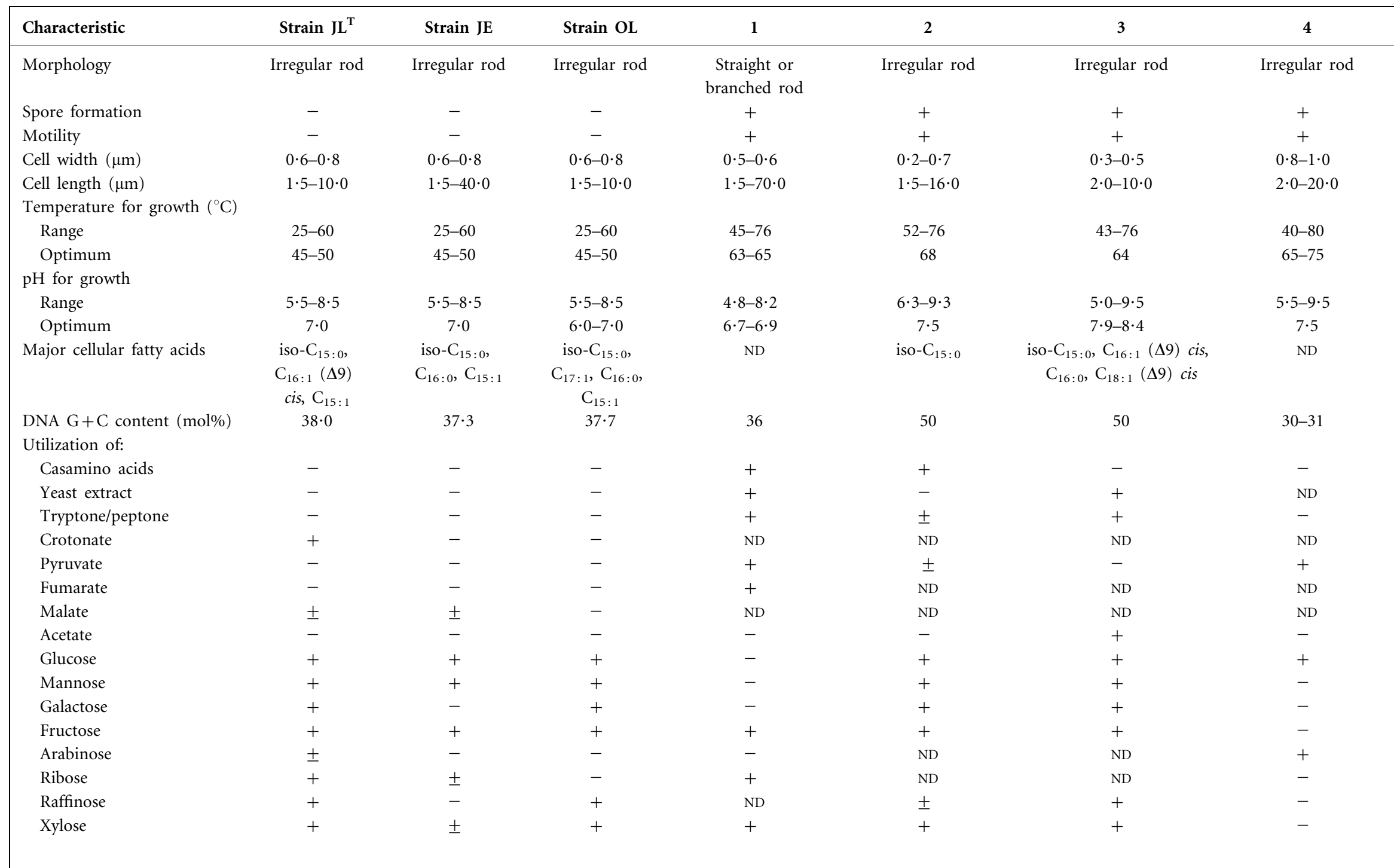




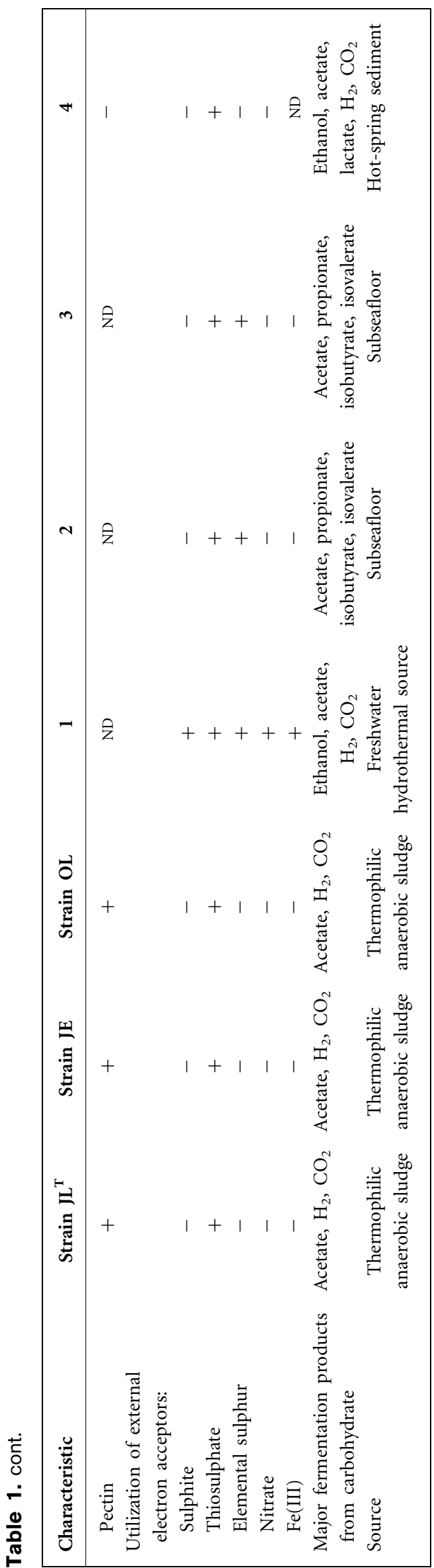

and lactate are important intermediates in the anaerobic degradation of organic compounds (such as carbohydrates) under thermophilic compounds (Stams \& Zehnder, 1990). Therefore, the strains could play a role in the degradation of such compounds in syntrophic association with methanogens in the digestion process. Moreover, the strains could degrade monomeric and polymeric carbohydrates such as starch and pectin, suggesting that they could act as polysaccharide degraders in organic solid wastes in sludge.

\section{Description of Tepidanaerobacter gen. nov.}

Tepidanaerobacter (Te.pi.da.nae.ro.bac'ter. L. adj. tepidus moderately warm; Gr. pref. an not; Gr. n. aer air; N.L. masc. n. bacter rod; N.L. masc. n. Tepidanaerobacter moderately thermophilic anaerobic rod).

Gram-negative. Cells are non-motile, rod- or filamentshaped. Spores are not formed. Moderately thermophilic. Cells grow under strictly anaerobic conditions. Neither photosynthetic nor aerobic growth is observed. The main fatty acids are iso- $\mathrm{C}_{15: 0}, \mathrm{C}_{16: 0}$ and $\mathrm{C}_{15: 1}$. Phylogenetic position is in a deeply branched lineage of the phylum Firmicutes. The type species is Tepidanaerobacter syntrophicus.

\section{Description of Tepidanaerobacter syntrophicus sp. nov.}

Tepidanaerobacter syntrophicus (syn.tro' phi.cus. Gr. pref. syn together with; Gr. adj. trophikos nursing, tending or feeding; N.L. masc. adj. syntrophicus pertaining to syntrophic substrate utilization).

Cells are irregular rods or sometimes filaments $(1.5$ to $>10 \mu \mathrm{m}$ long and $0 \cdot 6-0 \cdot 8 \mu \mathrm{m}$ wide). Growth occurs between 25 and $60{ }^{\circ} \mathrm{C}$ with optimum growth at $45-50{ }^{\circ} \mathrm{C}$. The $\mathrm{pH}$ range for growth is $5 \cdot 5-8 \cdot 5$; optimum growth occurs at $\mathrm{pH} 7 \cdot 0$. Yeast extract is required for growth. In the presence of yeast extract, growth and substrate utilization can be observed with the following substrates: glucose, xylose, fructose, mannose, sucrose, starch and pectin. Some strains utilize the following substances: crotonate, ribose, malate, arabinose, galactose and raffinose. Growth and acid formation in pure culture are not observed with the following substrates in the presence of yeast extract: yeast extract itself, Casamino acids, $\mathrm{H}_{2} / \mathrm{CO}_{2}$ plus acetate, tryptone, betaine, pyruvate, lactate, glycerol, acetate, propionate, butyrate, succinate, fumarate, ethanol, methanol, 1-propanol, 1-butanol, benzoate, hydroquinone, phenol, 1,3-benzenediol or formate plus acetate. Thiosulphate is used as an electron acceptor. None of the following compounds are utilized as electron acceptors: sulphate, nitrate, sulphite, elemental sulphur or Fe(III) NTA. Hydrogenotrophic methanogens can also be used as the electron-accepting system. In the presence of hydrogenotrophic methanogens, ethanol, glycerol and lactate are used. None of the following substances are used in coculture with methanogens: acetate, propionate, butyrate, methanol, 1-propanol, 1-butanol or benzoate. The G+C 


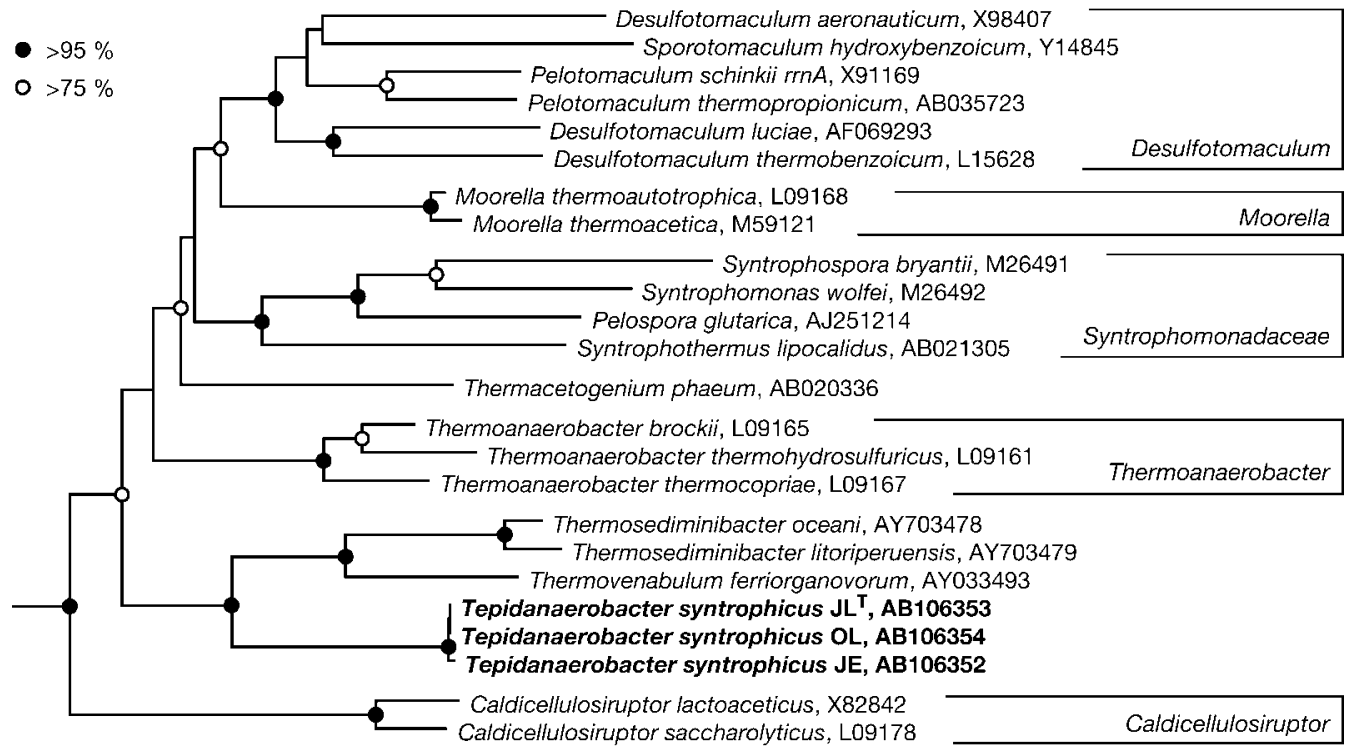

$0 \cdot 05$

Fig. 3. Phylogenetic position of strains $\mathrm{JL}^{\top}, \mathrm{JE}$ and $\mathrm{OL}$ among deeply branched groups of the phylum Firmicutes in the domain Bacteria; reference sequences are from the type strain of all species with the exception of the sequence for Moorella thermoacetica, which was obtained from strain ATCC 39073. 16S rRNA gene sequences of members of the Chlorobi were used to root the tree (not shown). Branching points supported with bootstrap probabilities above $95 \%$ by all the analyses (based on 1000 replicates, estimated using neighbour-joining, maximum-parsimony and maximum-likelihood methods) are indicated by solid circles, whereas nodes with open circles indicate $>75 \%$ bootstrap probability support by the three analyses. Branch points without circles were not highly resolved $(<75 \%)$ as specific groups in all analyses. Bar, 0.05 changes per sequence position.

content of genomic DNA of the three known strains is 37-38 $\mathrm{mol} \%$.

The type strain is $\mathrm{JL}^{\mathrm{T}}\left(=\mathrm{JCM} 12098^{\mathrm{T}}=\mathrm{NBRC} 100060^{\mathrm{T}}=\right.$ DSM $15584^{\mathrm{T}}$ ), isolated from sludge of thermophilic digesters that decompose organic solid wastes. Strains JE $(=\mathrm{JCM} 12099=\mathrm{NBRC} 100061=\mathrm{DSM} 15585)$ and OL $(=\mathrm{JCM} 12100=\mathrm{NBRC} 100062=\mathrm{DSM} 15586)$ are reference strains.

\section{Acknowledgements}

This study was supported financially by a research grant, subsidized by the Ministry of Education, Culture, Sports, Science and Technology, Japan, for the support of young researchers during their studies. This study was also carried out as a part of the Project 'Development of Technologies for Analysing and Controlling the Mechanism of Biodegrading and Processing', which was supported by the New Energy and Industrial Technology Development Organization (NEDO), Japan, and supported financially by research grant 1552481 from the Grants-in-Aid for Scientific Research subsidized by the Japan Society for the Promotion of Science (JSPS) in the 21st Century COE program 'Global Renaissance by Green Energy Revolution'. We thank Kanao Otake at Toray Industries, Inc. for his technical assistances on the cultivation and isolation of the strains obtained in this study. We also thank Xian-Ying Meng at the National Institute of Advanced Industrial Science and Technology (AIST) for transmission electron microscopy.

\section{References}

Ben-Bassat, A., Lamed, R. \& Zeikus, J. G. (1981). Ethanol production by thermophilic bacteria: metabolic control of end product formation in Thermoanaerobium brockii. J Bacteriol 146, 192-199.

Bryant, M. P., Wolin, E. A., Wolin, M. J. \& Wolfe, R. S. (1967). Methanobacillus omelianskii, a symbiotic association of two species of bacteria. Arch Mikrobiol 59, 20-31.

Bryant, M. P., Campbell, L. L., Reddy, C. A. \& Crabill, M. R. (1977). Growth of Desulfovibrio in lactate or ethanol media low in sulfate in association with $\mathrm{H}_{2}$-utilizing methanogenic bacteria. Appl Environ Microbiol 33, 1162-1169.

Cayol, J. L., Ollivier, B., Patel, B. K. C., Ravot, G., Magot, M., Ageron, E., Grimont, P. A. D. \& Garcia, J. L. (1995). Description of Thermoanaerobacter brockii subsp lactiethylicus subsp. nov., isolated from a deep subsurface French oil well, a proposal to reclassify Thermoanaerobacter finnii as Thermoanaerobacter brockii subsp. finnii comb. nov., and an emended description of Thermoanaerobacter brockii. Int J Syst Bacteriol 45, 783-789.

Doetsch, R. N. (1981). Determinative methods of light microscopy. In Manual of Methods for General Bacteriology, pp. 21-33. Edited by P. Gerhardt, R. G. E. Murray, R. N. Costilow, E. W. Nester, W. A. Wood, N. R. Krieg \& G. B. Phillips. Washington, DC: American Society for Microbiology.

Eichler, B. \& Schink, B. (1984). Oxidation of primary aliphatic alcohols by Acetobacterium carbinolicum sp. nov., a homoacetogenic anaerobe. Arch Microbiol 140, 147-152.

Felsenstein, J. (1985). Confidence limits on phylogenies: an approach using the bootstrap. Evolution 39, 783-791. 
Hanada, S., Takaichi, S., Matsuura, K. \& Nakamura, K. (2002). Roseiflexus castenholzii gen. nov., sp. nov., a thermophilic, filamentous, photosynthetic bacterium that lacks chlorosomes. Int J Syst Evol Microbiol 52, 187-193.

Hiraishi, A. (1992). Direct automated sequencing of $16 \mathrm{~S}$ rDNA amplified by polymerase chain reaction from bacterial cultures without DNA purification. Lett Appl Microbiol 15, 210-213.

Imachi, H., Sekiguchi, Y., Kamagata, Y., Hanada, S., Ohashi, A. \& Harada, H. (2002). Pelotomaculum thermopropionicum gen. nov., sp. nov., an anaerobic, thermophilic syntrophic propionate-oxidizing bacterium. Int J Syst Evol Microbiol 52, 1729-1735.

Jain, M. K. \& Zeikus, J. G. (1992). The genera Thermoanaerobacter, Thermoanaerobium, and other thermoanaerobic saccharolytic bacteria of uncertain taxonomic affiliation. In The Prokaryotes, 2nd edn, pp. 1901-1913. Edited by M. Dworkin, W. Harder \& K. H. Schleifer. New York: Springer.

Jobb, G., von Haeseler, A. \& Strimmer, K. (2004). TREEFINDER: a powerful graphical analysis environment for molecular phylogenetics. BMC Evol Biol 4, 18.

Kamagata, Y. \& Mikami, E. (1991). Isolation and characterization of a novel thermophilic Methanosaeta strain. Int J Syst Bacteriol 41, 191-196.

Klemps, R., Cypionka, H., Widdel, F. \& Pfenning, N. (1985). Growth with hydrogen, and further physiological characteristics of Desulfotomaculum species. Arch Microbiol 143, 203-208.

Lee, Y. J., Wagner, I. D., Brice, M. E., Kevbrin, V. V., Mills, G. L., Romanek, C. S. \& Wiegel, J. (2005). Thermosediminibacter oceani gen. nov., sp. nov. and Thermosediminibacter litoriperuensis sp. nov., new anaerobic thermophilic bacteria isolated from Peru Margin. Extremophiles 9, 375-383.

Ludwig, W., Strunk, O., Westram, R. \& 29 other authors (2004). ARB: a software environment for sequence data. Nucleic Acids Res 32, 1363-1371.

Pfenning, N. \& Wagener, S. (1986). An improved method of preparing wet mounts for photomicrographs of microorganisms. J Microbiol Methods 4, 303-306.

Plugge, C. M., Grotenhuis, G. G. \& Stams, A. J. M. (1990). Isolation and characterization of an ethanol-degrading anaerobe from methanogenic granular sludge. In Microbiology and Biochemistry of Strict Anaerobes Involved in Interspecies Hydrogen Transfer, pp. 439-442. Edited by J.-P. Belaich, M. Bruschi \& J.-L. Garcia. New York: Plenum.

Reddy, C. A., Bryant, M. P. \& Wolin, M. J. (1972). Characteristics of S organism isolated from Methanobacillus omelianskii. J Bacteriol 109, 539-545.

Roden, E. E. \& Lovley, D. R. (1993). Dissimilatory Fe(III) reduction by the marine microorganism Desulfuromonas acetoxidans. Appl Environ Microbiol 59, 734-742.

Saitou, N. \& Nei, M. (1987). The neighbor-joining method: a new method for reconstructing phylogenetic trees. Mol Biol Evol 4, 406-425.

Schink, B. (1984). Fermentation of 2,3-butanediol by Pelobacter carbinolicus sp. nov. and Pelobacter propionicus sp. nov., and evidence for propionate formation from $\mathrm{C}_{2}$ compounds. Arch Microbiol 137, 33-41.

Schink, B. (1985). Fermentation of acetylene by an obligate anaerobe, Pelobacter acetylenicus sp. nov. Arch Microbiol 142, 295-301.

Schink, B. (1997). Energetics of syntrophic cooperation in methanogenic degradation. Microbiol Mol Biol Rev 61, 262-280.

Schink, B. \& Stieb, M. (1983). Fermentative degradation of polyethylene glycol by a strictly anaerobic, Gram-negative, nonsporeforming bacterium, Pelobacter venetianus sp. nov. Appl Environ Microbiol 45, 1905-1913.
Sekiguchi, Y. \& Kamagata, Y. (2004). Microbial community structure and functions in methane fermentation technology for wastewater treatment. In Strict and Facultative Anaerobes: Medical and Environmental Aspects, pp. 361-384. Edited by P. Zuber \& M. M. Nakano. Wymondham, UK: Horizon Scientific Press.

Sekiguchi, Y., Kamagata, Y., Nakamura, K., Ohashi, A. \& Harada, H. (2000). Syntrophothermus lipocalidus gen. nov., sp. nov., a novel thermophilic, syntrophic, fatty-acid-oxidizing anaerobe which utilizes isobutyrate. Int J Syst Evol Microbiol 50, 771-779.

Sekiguchi, Y., Yamada, T., Hanada, S., Ohashi, A., Harada, H. \& Kamagata, Y. (2003). Anaerolinea thermophila gen. nov., sp. nov. and Caldilinea aerophila gen. nov., sp. nov., novel filamentous thermophiles that represent a previously uncultured lineage of the domain Bacteria at the subphylum level. Int J Syst Evol Microbiol 53, 1843-1851.

Shintani, T., Liu, W. T., Hanada, S., Kamagata, Y., Miyaoka, S., Suzuki, T. \& Nakamura, K. (2000). Micropruina glycogenica gen. nov., sp. nov., a new Gram-positive glycogen-accumulating bacterium isolated from activated sludge. Int J Syst Evol Microbiol 50, 201-207.

Stams, A. J. M. (1994). Metabolic interactions between anaerobic bacteria in methanogenic environments. Antonie van Leeuwenhoek 66, 271-294.

Stams, A. J. M. \& Zehnder, A. J. B. (1990). Ecological impact of syntrophic alcohol and fatty acid oxidation. In Microbiology and Biochemistry of Strict Anaerobes Involved in Interspecies Hydrogen Transfer, pp. 87-98. Edited by J.-P. Belaich, M. Bruschi \& J.-L. Garcia. New York: Plenum.

Swofford, D. L. (2003). PAUP* - Phylogenetic Analysis Using Parsimony ${ }^{\star}$ and other methods, version 4. Sunderland, MA: Sinauer Associates.

Wallrabenstein, C., Hauschild, E. \& Schink, B. (1995). Syntrophobacter pfennigii sp. nov., new syntrophically propionate-oxidizing anaerobe growing in pure culture with propionate and sulfate. Arch Microbiol 164, 346-352.

Weisburg, W. G., Barns, S. M., Pelletier, D. A. \& Lane, D. J. (1991). $16 \mathrm{~S}$ ribosomal DNA amplification for phylogenetic study. J Bacteriol 173, 697-703.

Widdel, F. \& Pfennig, N. (1981). Studies on dissimilatory sulfatereducing bacteria that decompose fatty acids. I. Isolation of new sulfate-reducing bacteria enriched with acetate from saline environments. Description of Desulfobacter postgatei gen. nov., sp. nov. Arch Microbiol 129, 395-400.

Wu, W.-M., Jain, M. K., Conway de Macario, E., Thiele, J. H. \& Zeikus, J. G. (1992). Microbial composition and characterization of prevalent methanogens and acetogens isolated from syntrophic methanogenic granules. Appl Microbiol Biotechnol 38, 282-290.

Zavarzina, D. G., Tourova, T. P., Kuznetsov, B. B., BonchOsmolovskaya, E. A. \& Slobodkin, A. I. (2002). Thermovenabulum ferriorganovorum gen. nov., sp. nov., a novel thermophilic, anaerobic, endospore-forming bacterium. Int J Syst Evol Microbiol 52, 1737-1743.

Zeikus, J. G., Hegge, P. W. \& Anderson, M. A. (1979). Thermoanaerobium brockii gen. nov. and sp. nov., a new chemoorganotrophic, caldoactive, anaerobic bacterium. Arch Microbiol 122, 41-48.

Zhang, H., Hanada, S., Shigematsu, T., Shibuya, K., Kamagata, Y., Kanagawa, T. \& Kurane, R. (2000). Burkholderia kururiensis sp. nov., a trichloroethylene (TCE)-degrading bacterium isolated from an aquifer polluted with TCE. Int J Syst Evol Microbiol 50, 743-749.

Zhang, H., Sekiguchi, Y., Hanada, S., Hugenholtz, P., Kim, H., Kamagata, Y. \& Nakamura, K. (2003). Gemmatimonas aurantiaca gen. nov., sp. nov., a Gram-negative, aerobic, polyphosphateaccumulating micro-organism, the first cultured representative of the new bacterial phylum Gemmatimonadetes phyl. nov. Int J Syst Evol Microbiol 53, 1155-1163. 